\author{
ARTIGO

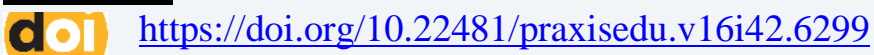

\title{
PEDAGOGIA CRÍTICA: TRANSFORMAÇÕES NOS SENTIDOS E NAS PRÁTICAS EMANCIPATÓRIAS
}

\author{
CRITICAL PEDAGOGY: TRANSFORMATIONS IN THE MEANINGS AND \\ EMANCIPATORY PRACTICES
}

\begin{abstract}
PEDAGOGÍA CRÍTICA: TRANSFORMACIONES EN LOS SIGNIFICADOS Y PRÁCTICAS EMANCIPATORIAS
\end{abstract}

\author{
Maria Amélia Santoro Franco \\ Universidade Católica de Santos - Brasil
}

\begin{abstract}
Resumo: Este artigo deve ser compreendido como um ensaio teórico e tem por perspectiva triangular criticamente pesquisas anteriores da autora, em diferentes espaços educativos, para fundamentar quer a epistemologia da pedagogia como teoria crítica, quer as possibilidades da práxis desta pedagogia. Para tanto, parte do conceito de ideologia proposto por Chaú e por meio deste conceito articula reflexões dos pressupostos da teoria crítica, com base em Adorno e Habermas, buscando evidenciar a síntese epistemológica de Paulo Freire na estruturação dos fundamentos da Pedagogia Crítica. Neste caminhar estabelece contrapontos com as teorias "críticas" da reprodução de Bourdieu, Passeron, Baudelot e Estabelet, Althusser e, por meio de triangulações entre os autores e a práxis educativa, reflete os sentidos de emancipação nos tempos atuais, buscando encontrar subsídios para a seguinte questão de pesquisa: pode a Pedagogia Crítica oferecer fundamentos para a construção de processos emancipatórios?
\end{abstract}

Palavras-chave: Pedagogia Crítica; emancipação; teorias critico-reprodutivistas

\begin{abstract}
This article should be understood as a theoretical essay and it aims to critically triangulate the author's previous research, in different educational spaces, to support both the epistemology of pedagogy as a critical theory and the possibilities of this pedagogy's praxis. Therefore, part of the concept of ideology proposed by Chauí and through this concept articulates reflections on the assumptions of critical theory, based on Adorno and Habermas, seeking to highlight the epistemological synthesis of Paulo Freire in structuring the foundations of Critical Pedagogy. In this way, it establishes counterpoints with the "critical" theories of the reproduction of Bourdieu, Passeron, Baudelot and Establet, Althusser and, through triangulations between the authors and the educational praxis, reflects the meanings of emancipation in the present times, seeking to find subsidies for the following research question: Can Critical Pedagogy offer foundations for the construction of emancipatory processes?
\end{abstract}

Keywords: Critical Pedagogy; emancipation; critical-reproductive theories

Resumen: Este artículo debe entenderse como un ensayo teórico y tiene como objetivo triangular críticamente la investigación previa del autor, en diferentes espacios educativos, para apoyar tanto la 
epistemología de la pedagogía como teoría crítica como las posibilidades de la praxis de esta pedagogía. Por lo tanto, parte del concepto de ideología propuesto por Chauí y a través de este concepto articula reflexiones sobre los supuestos de la teoría crítica, basados en Adorno y Habermas, buscando resaltar la síntesis epistemológica de Paulo Freire en la estructuración de los fundamentos de la pedagogía crítica. De esta manera, establece contrapuntos con las teorías "críticas" de la reproducción de Bourdieu, Passeron, Baudelot y Establet, Althusser y, a través de triangulaciones entre los autores y la práctica educativa, refleja los significados de la emancipación en los tiempos actuales, buscando encontrar subsidios para el siguiente pregunta de investigación: ¿puede la Pedagogía Crítica ofrecer fundamentos para la construcción de procesos emancipatorios?

Palabras clave: pedagogía crítica; emancipación teorías crítico-reproductivas;

\section{Introdução}

A educação brasileira, especialmente a pública, tem sido atingida por inúmeras tensões e desequilíbrios, que têm desestabilizado sua já frágil constituição histórica: quer pelo violento processo de mercantilização da educação, com vistas a atender os interesses do capital; quer pela dúbia destinação de verbas públicas para privilegiar e potencializar interesses privados e, no bojo disso tudo, o desvirtuamento pedagógico, privilegiando um ensino organizado para dar conta de exames e regulações externas; ensino esse que exclui das práticas pedagógicas o seu componente específico, qual seja, a formação de um pensamento crítico, autônomo e criativo. Ao lado disso, e por conta disso, as práticas pedagógicas têm se transformado em práticas dominadas, submissas, competitivas, meritocráticas, reprodutivistas e, como reforçaria Paulo Freire, práticas meramente bancárias.

Neste sentido, é fundamental que recorramos à pedagogia crítica, como princípio, como conceito e como epistemologia, para situá-la, primeiramente como a perspectiva da educação que queremos, em contraposição aos rumos inquietantes que temos observado acontecer nos últimos anos desta década, em relação à transformação da educação em práticas autoritárias de controle e de regulação. Como fala Giroux (2019): Pedagogia Crítica é uma revisão do tipo de escola que queremos.

Para realizar essa revisão vamos nos fazer acompanhar do conceito de ideologia proposto por Chauí (2016):

A noção de ideologia pode ser compreendida como um corpus de representações e de normas que fixam e prescrevem de antemão o que se deve e como se deve pensar, agir e sentir. Com o objetivo de impor os interesses particulares da classe dominante, esse corpus produz uma universalidade imaginária. A eficácia da ideologia depende, justamente, da sua capacidade de produzir um imaginário coletivo em cujo interior os indivíduos possam 
localizar-se, identificar-se e, pelo autorreconhecimento assim obtido, legitimar involuntariamente a divisão social. Sua coerência está atrelada a uma lógica da lacuna e do silêncio sobre sua própria gênese, isto é, sobre a divisão social das classes. (CHAUÍ, 2016, p. 245)

Está claro que há outras perspectivas ao conceito de ideologia, no entanto, para efeito de discussão do conceito de Pedagogia Crítica, atrelada à compreensão de processos emancipatórios, é fundamental atentarmos à questão da prescrição de modos de pensar e agir, que estão assim sistematizados, para impor interesses particulares da classe dominante, que legitimam uma divisão de classes sociais, divisão essa que tende a se perpetuar pelos silêncios e lacunas que são postos nesse "engessamento" cultural da/na sociedade.

Percebe-se a imensa tarefa que é posta à educação e que foi tão insistentemente analisada por Freire em toda sua obra, especialmente na Pedagogia do Oprimido (1997): é preciso des-ocultar a ordem prévia que estrutura a sociedade; é fundamental que cada sujeito aprenda a identificar seu local social, para que deste lugar apreenda a lógica de domesticação que o sistema social impõe. Dentre outras afirmações, ele realça a necessária atitude de conhecer os condicionantes que nos cercam como sujeitos históricos:

A necessária formação técnico-científica dos educandos por que se bate a pedagogia crítica não tem nada que ver com a estreiteza tecnicista e cientificista que caracteriza o mero treinamento. É por isso que o educador progressista, capaz e sério, não apenas deve ensinar muito bem sua disciplina, mas desafiar o educando a pensar criticamente a realidade social, política e histórica em que é uma presença. (FREIRE, 2000, p. 43 - 44).

Componente essencial à pedagogia crítica é a insistência na organização de práticas educativas com vistas a facilitar a cada sujeito, compreender o seu lugar social e, a partir deste, decifrar as lógicas que articulam a realidade social mais ampla, de forma a conhecer e talvez tensionar, as lacunas e silêncios que perpassam a estrutura ideológica da sociedade.

A ausência de uma pedagogia crítica faz reificar a relação de opressão que a própria dinâmica ideológica social faz operar. Assim, Freire insiste na necessidade de libertação do oprimido de suas condições e perspectivas opressoras.

Somente na medida em que se descobrem hospedeiros do opressor poderão contribuir para o partejamento de sua pedagogia libertadora. Enquanto vivam a dualidade na qual ser é parecer e parecer é parecer com o opressor, é impossível fazê-lo. A pedagogia do oprimido, que não pode ser elaborada pelos opressores, é um dos instrumentos para esta descoberta crítica - a dos oprimidos por si mesmos e a dos opressores pelos oprimidos, como manifestações de desumanização. (FREIRE, 1997, p. 43). 
Encontra-se, talvez, nesta contradição entre opressor e oprimido, as raízes da compreensão dos sentidos de emancipação, sentidos esses atrelados a processos de formação e conscientização, base da perspectiva de uma educação ou de uma escola, que se fazem críticas, de modo a produzir condições de humanização. Assim, vamos analisar a constituição dos processos de emancipação, conforme alguns autores críticos.

\section{Educação crítica e emancipação}

Temos observado que o conceito de emancipação tem sido desvirtuado e está sendo absorvido dentro do discurso neoliberal, confundindo-se com o sentido de empreendedor; ou de sujeito empoderado; ou de vencedor. É bom que se lembre que este conceito, tanto para Freire, como para Marx, ou mesmo para os teóricos da teoria crítica como Adorno ou Habermas, está sempre vinculado à perspectiva do coletivo, do homem como sujeito social e assim bem se expressa Marx, em análise realizada por Schimied-Kovarzik:

Toda emancipação é recondução do mundo humano, das relações existentes ao homem como tal [...] Só quando o homem individual verdadeiro, vier a absorver em si o cidadão abstrato, tornando-se, na sua vida empírica, no seu trabalho individual, um ser genérico; só quando o homem vier a reconhecer e organizar suas próprias forças enquanto forças sociais, de modo a não mais separar de si a força social na sua configuração política, só então será cumprida a emancipação humana. (MEW 1,370) ${ }^{1}$.

Assim, é preciso realçar que emancipação não é uma categoria pessoal, é uma categoria coletiva, política e social; e o conceito é bastante trabalhado por Freire na Pedagogia do Oprimido, onde, dentre outras coisas afirma: "a emancipação só faz sentido se os oprimidos buscarem a reconstrução de sua humanidade e realizarem a grande tarefa humanística e histórica dos oprimidos: libertar-se a si e aos opressores” (FREIRE, 1997, p. 30).

Rúrion Melo (2011) realça que aquilo que reafirma uma concepção de teoria crítica consiste em seu interesse pelas condições emancipatórias socialmente existentes num dado momento histórico, bem como na análise dos obstáculos existentes à emancipação. Requer-se um diagnóstico crítico voltado para o problema da orientação emancipatória.

As patologias da modernidade, produzidas pela imposição hegemônica da razão instrumental, manifestam-se nos campos da moral, da ciência e da arte. É resultado de uma economia capitalista monopolista, que conta com ampla intervenção do Estado sobre a vida dos indivíduos e cria as condições

${ }^{1}$ Marx, K. apud Schimied -Kowarzik: IN: Schimied- Kowarzik. Práxis e responsabilidade. EDUPUCRS. 2002. P.49 
favoráveis para a implementação de um mundo totalmente administrado. Encontra-se obstruída, portanto, toda a possibilidade de emancipação e, por sua vez, a própria relação entre teoria e práxis. (HORKHEIMER, 2008, p.136, apud MELO, 2011).

As contradições decorrentes das esperanças colocadas pelo iluminismo de um lado, e desencantos decorrentes da própria epistemologia do iluminismo, de outro lado, são analisadas por muitos autores, especialmente Adorno e Horkheimer, e até Max Weber ${ }^{2}$, enfatizando que, ao mesmo tempo em que a racionalidade iluminista surge como grande perspectiva de libertação social, de destruição de mitos, de emancipação dos homens; esta transforma-se e consolida-se como ideologia de dominação, que legitima a sociedade capitalista, convertendose em processo de dominação do homem, num mundo administrado pela razão instrumental.

Habermas vai estudar profundamente essa questão, propondo a superação do paradigma da consciência pelo paradigma da comunicação, alertando-nos para o fato de que a perspectiva objetivista, positivista, posta pela ciência, pautada em verdades exatas e mensuráveis, tira do sujeito sua referência cognoscente. Diante das certezas e da impossibilidade de um conhecimento sensível e autoconstruído, este (conhecimento) atrela-se à perspectiva de dominação, de instrumentalização, dificultando as possibilidades de um conhecimento crítico, auto reflexivo. Assim, Habermas (2014) se explicita:

Não é permitido à comunidade dos pesquisadores perceber-se como sujeito da reflexão: sua atitude cientificista fundamental obriga-a à auto objetivação. Assim, o teórico cientificista da ciência tem de rejeitar a exigência da autorreflexão- à qual não poderia ceder sem abandonar sua teoria-indicando o programa que, uma vez executado, tornará sem objeto todas as exigências de autorreflexão. (HABERMAS, 2014, p. 449)

Considero que são questões importantes postas por Habermas ao analisar uma das referências fundamentais à teoria crítica, qual seja, as possibilidades da emancipação dos homens e, em decorrência, um sinal para nós, educadores críticos e reflexivos, em relação às dificuldades e perspectivas da pedagogia crítica, cuja prática se realiza na contrapartida da não dominação; na intencionalidade de criar práticas educativas, que possam abrir possíveis caminhos de emancipação.

Habermas (1987) cria o conceito de mundo da vida, para nos fazer compreender a sociedade como uma entidade que, no correr da evolução, diferenciou-se tanto como um sistema quanto como um mundo da vida. (HABERMAS, 1987, p. 152).

\footnotetext{
${ }^{2}$ Vide, dentre outros a questão do desencantamento do mundo tão bem analisada por Max Weber. SOUZA, Jessé (Org.). A atualidade de Max Weber. Brasília: Universidade de Brasília, 2000. WEBER, M. A ética protestante e o "espírito" do capitalismo. São Paulo: Companhia das Letras, 2004.
} 
Entende-se pela lógica de Habermas que mundo da vida e mundo do sistema vão se descolando, criando rompimentos entre os saberes do sistema e do mundo cotidiano da vida, instituindo distanciamentos entre o saber intuitivo da prática comunicativa e o saber estruturado do mundo do sistema. O mundo do sistema proporá, através de suas instituições, práticas e processos institucionais voltados à colonização do mundo vida.

O sistema é regido pela razão instrumental e compreende dois subsistemas: o econômico e o político. O mundo da vida compreende as intersubjetividades dos atores inseridos em situações concretas de vida, constituindo-se no pano de fundo sobre o qual ocorrem as ações (HABERMAS 2001)

As duas lógicas combatem-se e convivem: a razão instrumental e a razão comunicativa. Nesses processos contraditórios e complementares, surgem mecanismos de opressão e de resistência.

É nesta perspectiva que o sentido da emancipação adquire uma nova possibilidade: ao dialogar, reinterpretar, usar códigos específicos de linguagem, o mundo vida tem alternativas de descolonização. É na análise deste mundo vital que Habermas encontra a saída para a razão, para a moral, pois podendo analisar, discutir, problematizar o mundo da vida é que os indivíduos poderão se descolonizar do sistema, ou conforme Freire, buscar caminhos de conscientização. Neste meandro de significados coloca-se a pertinência da Pedagogia Crítica.

Como produzir processos pedagógicos de/para emancipação? Muitos autores nos ajudam a pensar: começamos com CHAUÍ (2016, p. 245); passamos por HABERMAS (2001); sempre com FREIRE (1997, 1984, 2000). Mas há obstáculos e dificuldades: a pedagogia crítica sozinha não tece as condições necessárias e suficientes para dinamizar práticas emancipatórias. Muitos autores ajudam e aqui neste artigo, vamos dar realce aos estudos críticos de ADORNO $(1985 ; 1995)$ no estabelecimento de questões que impedem os processos emancipatórios. Dentre estas, pode-se realçar:

- Na sociedade capitalista há um processo real que produz o alheamento do homem das suas condições reais de vida; esse alheamento coloca o sujeito em condições de despersonalização, o que dificulta seus mecanismos de buscar a emancipação, reificando sua condição de oprimido e colonizado;

- A crise da educação é a crise da formação cultural da sociedade capitalista: uma formação que faz o homem alienado, mesmo que tenha sido supostamente educado/escolarizado/instruído; realce para indústria de entretenimentos que tira do homem sua possibilidade de dialogar com a cultura, estando e ficando à mercê da 
indústria cultural que seduz e instiga à não participação, ao consumo da subcultura e abandono das formas de produção crítica da cultura;

- Os processos de homogeneização de práticas e costumes, retira do sujeito as possibilidades de individuação, despersonaliza o homem, exclui a particularidade; a individualidade; fortalecendo mecanismos e movimentos de massa que geram e perpetuam processos de opressão; produzindo os métodos de domínio da fala; das interpretações, do mundo vida;

- Os processos de avanço da semiformação, sofisticados hoje com o uso de tecnologias de reprodução. Lembrando ainda que o sentido de semiformação não significa uma formação incompleta, o que supostamente poderia ser a posteriori completada; mas seu sentido é de uma formação fragilizada, abreviada; apequenada. Adorno realça e abre críticas à ideologia do sistema de ensino: na ideologia da igualdade, uma prática desigual; escola reforça o domínio da ideologia dominante;

As preocupações de Adorno, não são a princípio pedagógicas, são filosóficas, mas rebatem nas questões postas à Pedagogia Crítica. Ajudam a responder à pertinente questão colocada por Giroux (1983, p. 3), quando pergunta: quando poderemos tornar a educação criticamente significativa e, como é que, sendo crítica, podemos torná-la emancipatória? Como eu realcei acima: não basta ser crítica a educação; será preciso que ela se torne emancipatória e, nesta perspectiva, a escola sozinha não caminha; será preciso a adesão de boa parte da sociedade.

\section{As teorias critico-reprodutivistas e a pedagogia critica}

A emergência das TCR ${ }^{3}$ ocorre na Europa, especialmente França, nas décadas de 60 e 70 do século passado e, nós brasileiros, que nessa época estávamos em regime ditatorial, recebemos sua influência, como um reforço aos mecanismos de resistência às práticas educacionais opressoras da ditadura, ou como escreve Saviani (2013, p.397), as análises decorrentes das TCR funcionaram como armas teóricas utilizadas para fustigar a política educacional do regime militar, uma vez que, o regime ditatorial realmente utilizava a escola como mecanismo de controle da sociedade, visando perpetuar relações de dominação.

Segundo Charlot (2013), entre as décadas de 60 e 70 do século passado houve um grande movimento de pesquisadores que absorveram as teses reprodutivistas e passaram a

${ }^{3}$ Teorias critico-reprodutivistas. 
pesquisar os mecanismos que permitiam à escola servir aos interesses capitalísticos e produzir práticas sorrateiras, disfarçadas, que dificultavam a presença/permanência e desempenho das classes populares na escola. Desta forma, foi grande o mérito dos estudos decorrentes destas teorias, porque deram sustentação teórica à crítica de uma pedagogia tecnicista, que servia aos propósitos da lógica econômica e assim, por meio deste respaldo teórico, pode-se tensionar o mito de que a escola era a redentora da classe popular e que através dela a classe operária poderia ascender socialmente. No entanto, o movimento deixou bem clara a concepção de que a escola, tal como era, servia para referendar e manter as desigualdades sociais. ${ }^{4}$

Esses estudos vão realçar como as práticas utilizadas pelas escolas para produzir disciplina, respeito à hierarquia; submissão; verdades únicas, uniformização de comportamentos e posturas, eram na realidade, práticas opressoras e que oprimiam, especialmente, a classe popular e que dissimulavam com o discurso de equanimidade, esse caráter opressor. Tudo parecia bem naturalizado e assim, a criança de classe popular, que não possuía o mesmo capital cultural de alunos de outras classes sociais; havia que se submeter à lógica de uma escola que era construída para a lógica da dominação, apequenando as possibilidades da classe social popular encontrar o mesmo êxito que outros alunos, que já circulavam nessa mesma lógica e possuíam um capital cultural adequado às cobranças escolares.

Enfim, os mecanismos escolares que perpetuam as desigualdades que se concretizam no âmbito escolar tornam-se, através dessas teorias reprodutivistas, mais explícitos, esclarecendo práticas de simulação de igualdade, onde vigorava tratamentos iguais para crianças diferentes ${ }^{5}$ e assim, tais teorias ajudaram a produzir uma nova compreensão do papel da escola como aparelho ideológico do estado.

Segundo Althusser (1970, p 32), pesquisador destas teses reprodutivistas, a escola se constitui como um dos principais aparelhos ideológicos do Estado, pois funciona como regulador e controlador das massas, tornando as práticas escolares responsáveis para preparar mão de obra para as indústrias, consumando a ideologia da alta burguesia dominante. No entanto, realça que a escola não é o único AIE, há a igreja, família, instituições políticas, jurídicas diversas:

\footnotetext{
${ }^{4}$ Para análise mais aprofundada dessas teorias vide ALTHUSSER, 1992. Aparelhos ideológicos do estado. Biblioteca Ciências Sociais. BOURDIEU, P.; PASSERON, R. A reprodução: elementos para uma teoria de ensino. Rio de Janeiro. Francisco Alves. 1992. Dentre outros

${ }^{5}$ Vide: BAUDELOT, Christian; ESTABLET, Roger. La escuela capitalista. 10. ed. México: Siglo XXI, 1987
} 
Todos os aparelhos ideológicos de Estado concorrem para o mesmo resultado: a reprodução das relações de produção, isto é, das relações de exploração capitalistas. Cada um deles concorre para esse resultado de uma maneira que lhe é própria, isto é, submetendo (sujeitando) os indivíduos a uma ideologia. ALTHUSSER (1970, p 32),

No entanto, o tempo mostrou que é preciso relativizar a influência dos mecanismos de repressão desencadeados pelos AIE. Se estes estudos nos mostraram essa perspectiva, também outros estudos decorrentes nos mostram que nem tudo ocorre em direção única. Há sempre reações e resistências.

Bernard Charlot, em entrevista a Jaime Giolo (2005, p.19), afirma que Bourdieu, um dos principais representantes das TCR, desenvolveu a análise do sistema educacional em termos de posição social. Charlot diz, que a princípio concorda com a tese; no entanto diz que isso não é tudo!

Diz Charlot: "deve-se ir além de uma análise em termos de posições sociais!” Alerta o pesquisador que há algo além das sociologias da reprodução; esclarecendo que há uma infinidade de práticas que se colidem e se articulam na vida dos sujeitos. Assim afirma: "as atividades são socialmente definidas, mas são também atividades de um sujeito". Acredito que este raciocínio do autor, já presente em sua obra maior A Mistificação Pedagógica, ${ }^{6}$ seja a base na qual fundamentou sua teoria "da relação com o saber", onde realça que há uma posição social, objetivamente determinada; mas há também, e concomitantemente, uma posição subjetivamente determinada, e isso muda tudo!

A partir desse raciocínio de Charlot, outras avaliações se somam e considera-se hoje, com alguma unanimidade, que as teorias crítico-reprodutivistas, ao lado do caráter elucidador dos mecanismos de regulação social, foram também reducionistas na análise social; carregam princípios funcionalistas; trabalharam numa perspectiva a-históricas; ignoraram conflitos e contradições e também desconsideraram as resistências que estão continuamente operando no mundo vida, onde o imprevisível sempre pode ocorrer. Essas teorias foram redutoras da complexidade da dinâmica social da educação.

Há que se realçar que as teses reprodutivistas, ao mesmo tempo em que produziram fissuras nas subjetividades a respeito do papel redentor da escola, produziram outras interpretações à teoria crítica, demonstrando a possibilidade real do uso da escola como aparelho regulador do estado, exprimindo bem o conceito de Chauí retomado nesta introdução, de uma ideologia mascarada, disfarçada, o que permitiu que compreendêssemos melhor o

\footnotetext{
${ }^{6}$ Publicado em 1975 e traduzido no Brasil em 1979, agora reeditado e ampliado pela Cortez editora em 2014.
} 
fenômeno de dominação cultural analisado por Adorno (ideologização do capital cultural) e estas compreensões fizeram com que novos estudos fossem elaborados e assim, fortaleceram os pressupostos e práxis da Pedagogia Crítica.

Pode-se afirmar que a Pedagogia Crítica considera os pressupostos das TCR, mas vai além, superando-a ao acrescentar a dialética da resistência e dominação, como dinâmica de sentido às práticas escolares

\section{Pedagogia crítica: o papel de Paulo Freire}

Na confluência do contexto político cultural, que antecedeu ao golpe militar de 1964, com a expansão de movimentos educacionais de base e o novo papel exercido pela Igreja Católica, surgiu o importante movimento epistemológico da pedagogia brasileira: A Pedagogia do Oprimido, com Paulo Freire, que carrega as características de uma pedagogia críticoemancipatória, embora não exclusivamente.

Esta pedagogia vem conferir um novo panorama à epistemologia pedagógica, mesclando diversas concepções filosóficas, carregando uma proposta eminentemente política, não conivente com a da ideologia da classe dominante. Mesmo tendo sido um processo precocemente abortado pelo golpe militar de 1964, suas raízes estavam fincadas, e germinaram em outros espaços e tempos.

A Pedagogia do Oprimido surge como um rompimento epistemológico e político frente ao que se desenhava como perspectiva política da educação e mais que tudo, surge como uma resistência à lógica liberal e tecnicista que marcava a história política do Brasil até aquele momento.

Em poucas palavras, a pedagogia crítica tem envolvido um esforço complexo, de ligação entre a teoria crítica e as práticas educativas tal como entendidas por Freire: a relação entre reprodução societal e educação; uma sociologia estrutural do currículo; uma compreensão interacionista das atividades da sala de aula e do papel do professor, isso em termos de relações de poder que definem a educação em relação à constituição do pacto democrático de determinadas sociedades. (TORRES; MURROW, 1998 p. 140).

É exatamente esta questão que foi diretamente abordada por Freire: não era apenas uma teoria social crítica; mais que isso, o que ele propunha era uma maneira inevitável, inexorável de ser e estar educador: assumir um papel social a favor dos "esfarrapados da vida" e dar-lhes os instrumentos para tensionar as relações de poder postas historicamente. 
A partir desta consideração, onde se alia teoria crítica e prática pedagógica emancipatória é que se torna possível afirmar: ou a pedagogia se assume com os sujeitos, na luta coletiva por sua emancipação; ou deixa de ser pedagogia, passando a ser uma tecnologia social de dominação

O trabalho pedagógico de Paulo Freire com a educação de adultos, carrega e favorece um grande rompimento epistemológico com a intencionalidade da educação vigente no Brasil. Até então, pressupunha-se a educação como uma forma de encaminhar os educandos à cultura letrada da elite e Paulo Freire recoloca esta situação, no sentido de alertar que a educação tem por finalidade a humanização do próprio homem e deve ser um instrumento que permite ao educando ressignificar sua humanidade, redescobrir seu lugar no mundo, amalgamar-se com sua cultura, dela se fazer um elemento e transformar essa cultura à medida que a apreende e se transforma como elemento da cultura.

Portanto a educação passa a ser vista não mais como instrumento que deve propiciar a posse de uma cultura estranha e construída por outros, mas um processo de realizar nos educandos a possibilidade de se tornarem homens em plenitude, produtores, interpretadores de cultura e capazes de apreender e construir cultura.

Enfim, a educação se destina a formar homens ou a dotá-los de conhecimentos previamente selecionados e julgados por outros, como sendo os necessários? Essa questão ainda permanecesse em nosso Brasil do século XXI!!!!

Está certo que Paulo Freire não descarta a importância da cultura letrada, no entanto é uma questão de encarar o fenômeno da relação homem mundo de maneira diferente: antes de ser método e técnica de transmissão, a educação deve ser um ato político, que organiza a intencionalidade do ensino, a partir do sujeito, visto sempre em seu coletivo social. Paulo Freire não desconsiderava o papel da informação, mas considerava que as informações de nada servirão se, paralelamente ao ato de conhecer, o sujeito não criar uma "nova teoria do conhecimento" que será a matriz de um novo quadro interpretativo, que irá permitir ao aluno reelaborar seus conhecimentos dentro de uma nova ótica, a ótica do sujeito. ${ }^{7}$

A obra de Freire no Brasil foi bruscamente interrompida, ${ }^{8}$ mas teve diversas continuidades no mundo, demonstrando sua pertinência como fundamento de uma pedagogia que aliando ciência, arte e política, influenciou outras áreas do saber e apresentou diretrizes que

\footnotetext{
${ }^{7}$ Vejo muita similaridade deste conceito de Paulo Freire com a atual proposta de Charlot (2000) quando se refere ao fato de que o sujeito, aluno, precisa construir novas relações com o saber, de forma que o conhecimento tenha sentido ao sujeito.

${ }^{8}$ Sua obra foi interrompida logo após o golpe militar de 1964, que instituiu mais uma vez a ditadura militar em nosso país.
} 
foram profundamente utilizadas por vários trabalhadores sociais em suas práticas: filósofos, terapeutas, médicos, cientistas. Sua obra prenunciou um tratamento interdisciplinar das ciências, enriquecendo o trabalho de educadores com novas formas de pesquisa, como a pesquisa participante, demonstrando que a Pedagogia pode ser uma ciência articuladora de saberes e também instrumento fundamental, essencial, à emancipação da humanidade.

Freire, em seu último trabalho, "A Pedagogia da Autonomia", realça a questão dos saberes necessários à prática educativa, que extrapolando os saberes já cristalizados, podem, via um trabalho reflexivo e transformador, redundar numa leitura crítica das condições de degradação da humanidade, e assim fundamentar as condições de um saber fazer crítico e emancipatório que, alicerçado no desejo e na alegria, mas sem abrir mão do rigor, da seriedade e simplicidade do fazer competente, poderá redirecionar os descaminhos tomados pela humanidade em relação à construção da dignidade humana.

Considero Freire o principal ideólogo da Pedagogia Crítica, ou seja, construtor de uma pedagogia que tem como perspectiva a formação e emancipação dos sujeitos em situação de opressão, uma pedagogia não prescritiva e que se constrói na práxis e para a práxis emancipatória.

\section{Condições de uma emancipação pela pedagogia}

Acredito que compete à educação e à Pedagogia, colocar-se sempre na condição de possibilidade: nada a princípio é impossível, mas nem tudo é possível! Há limites e possibilidades, bem expressas pela Pedagogia da Esperança enunciada por Freire (1986). Já aqui afirmamos que, se a pedagogia crítica pode restaurar caminhos possíveis, esta sozinha não caminha além de suas pontes e passarelas. A Pedagogia insere-se num conjunto de múltiplas determinações e pode ser apenas compreendida nas possibilidades postas pelas relações de contradições que vão se constituindo. Assim, acredito que só seja possível falar de emancipação como um processo/projeto social que se institui e é instituído pelas relações contraditórias no espaço tempo sócio-histórico-cultural.

Estudos recentes (Giroux, 1983; Silva, 2002) têm renovado a compreensão já bastante consensual, de que as escolas e demais espaços educativos não são meros reflexos dos interesses dominantes da sociedade. Esses espaços, especialmente os de caráter público, são também espaços de resistência e de contestação, o que gera uma força contínua entre o possível e o provável; entre o hegemônico e o contra hegemônico. 
Concordo com Giroux (1983) quando analisa a importância dos estudos críticos como os de Adorno, Horkheimer, Habermas, dentre outros, por mostrarem possibilidades de uma investigação mais abrangente na multiplicidade de fenômenos socioculturais que perpassam o cotidiano educacional, tanto na perspectiva de dominação, como na perspectiva de novas interpretações e possibilidades emancipatórias.

Essa contradição entre possibilidade e reificação abre a perspectiva para reafirmarmos a necessidade de uma pedagogia mais alargada, mais crítica, que rompa com paradigmas positivistas que ainda impregnam, apequenam e distorcem as práticas escolares. Uma prática educacional positivista é aquela, segundo Giroux, que prioriza os mecanismos racionais da prática e eleva a metodologia de ensino a um estatuto de verdade. Ou seja, a supremacia metodológica, técnica, acaba funcionando como condição de controle, na perspectiva instrumental e não dialógica.

Quando Paulo Freire insiste na superação de uma educação bancária, o que ele por certo realça é que, ao superar a dimensão bancária e adentrar na educação libertadora, superase esta dimensão castradora, positivista da educação e pode-se enfrentar a contradição e assim, adentrar nas possibilidades de superação da dominação. Quando Freire insiste na dialética educador/educando ou opressor/oprimido ele o faz, não apenas para polarizar; mas por considerar a inexorabilidade da contradição! Por isso erige uma filosofia da práxis: atrelando resistência e consciência e compromissos mútuos, na compreensão dos fatores que geram desigualdade. A luta, na/pela contradição, é que significa para Pulo Freire a possibilidade de emancipação.

Esse cenário nos induz à Pedagogia Crítica tanto na formação dos professores, quanto nas práticas escolares cotidianos. Será preciso que professores percebam as possibilidades da escola como espaço de contestação e de resistência, de forma a produzir processos que possam romper com a lógica possível da dominação pelas práticas escolares. É preciso repensar práticas pedagógicas que carreguem a contra hegemonia de muitos séculos de dominação pela escola. Precisamos que as escolas resgatem e construam espaços de questionamento; de diálogos formativos; de ressignificação da cultura escolar; de partilha de significados e de um currículo que expanda e fortaleça as oportunidades emancipatórias. Esclarecimentos críticos ao invés da tutela da informação; práticas de convivência construtiva e dialógica, ao invés de mecanismos de reprodução do saber; de disciplina castradora. Que todos na escola construam a capacidade de falar pela própria boca, de pensar pelos próprios parâmetros e de dialogar para a construção 
de novos saberes. É preciso fazer da educação escolar um programa deliberado de resistência, consciência e formação.

\section{Por novas apostas à pedagogia}

Seguindo reflexões realizadas por FRANCO, MOTA e SILVA (2020) a tarefa da humanização, anseio da prática pedagógica, nunca está concluída e esbarra continuamente nas tentativas de submissão do ser humano às condições de subumanidade, às vezes francamente explícitas, às vezes disfarçadas em slogans de 'progresso', de 'desenvolvimento', de ascensão ao estágio atual da modernidade, ao 'empoderamento' pessoal e social como o que vem sendo produzido ostensivamente pela fábrica de ilusão de propaganda neoliberal (de base capitalista), forjando a emergência de uma nova racionalidade, que está a se tornar hegemônica:

As formas de gestão na empresa, o desemprego e a precariedade, a dívida e a avaliação, são poderosas alavancas de concorrência interindividual e definem novos modos de subjetivação. A polarização entre os que desistem e os que são bem-sucedidos mina a solidariedade e a cidadania [...] tudo parece conduzir à destruição das condições do coletivo... (LAVAL/DADOT, 2016, p. 9).

Os autores deixam explícitas as agudas urgências que são postas à Pedagogia que se quer crítica, em contraponto e resistência à ideologia neoliberal, que, passando do âmbito social, adentra o ambiente educacional e cria subjetivações capitalísticas, tais como: a competição, a concorrência, a escola como empresa a ser gerenciada e avaliada pela lógica de custo/benefício, a lógica da meritocracia (que hierarquiza os sujeitos em vencedores e perdedores), a exacerbação da liberdade de expressão e o definhamento do senso coletivo, da cidadania e do bem público. Tudo passa pela lógica da privatização, da meritocracia individual: tanto o sujeito como a família, a escola, os amigos, as relações sociais, a democracia, o espaço público, a cidade, a nação, o Estado, os recursos naturais.

Também a que se considerar que outra urgência posta à Pedagogia crítica é o enfrentamento à lógica utilitarista advinda da pressão do setor financeiro nacional e internacional. Essa subjetivação neoliberal, em que o ser humano, em última instância, tem suas dimensões - intelectual, psicológica, afetiva, social, cultural, religiosa - convertidas ao "homem econômico" seduziu eficazmente o mundo da educação ao ser submetido de forma aguda pelo Consenso de Washington, em 1989, à vertente mercadológica, urgência que está em andamento na Organização Mundial do Comércio (OMC), com o Acordo Geral sobre o Comércio de Serviços (AGCS). Basicamente preconiza a desregulamentação, isto é, a não- 
intervenção do Estado, em todas as atividades econômicas como condição sine qua non para o desenvolvimento econômico e social em todos os países.

O neoliberalismo globalizado tem tirado o protagonismo das decisões pedagógicas sobre a prática educativa e assim se manifestado de forma cruel à prática pedagógica criando projetos para financiar redes de escolas particulares, produzindo um verdadeiro mercado de educação.

Freire (1999) há 20 anos atrás, já alertava para a "malvadeza" da ética do mercado a que estamos expostos e que, a cada vez mais nos comanda:

[...] Há um século e meio Marx e Engels gritavam em favor da união das classes trabalhadoras do mundo contra sua espoliação. Agora, necessária e urgente se fazem a união e a rebelião das gentes contra a ameaça que nos atinge, a da negação de nós mesmos como seres humanos submetidos à "fereza" da ética do mercado (FREIRE, 1996, p. 144-145).

Frente à perspectiva impregnante das políticas neoliberais e do império do mercado, que produz a imagem de uma humanização à custa e em proveito do consumo, qual seria a possibilidade de uma perspectiva emancipatória à humanização, a ser incorporada à epistemologia crítica da Pedagogia? Talvez seja uma questão que requer um novo diagnóstico crítico que desvele os equívocos de tantas políticas públicas que desconsideram a urgente necessidade de descolonizar a educação e de buscar novos sentidos e novas articulações com fins de diminuir as distâncias abissais que permanecem e ainda estruturam a sociedade brasileira.

\section{REFERÊNCIAS}

ADORNO, Theodor Ludwig Wiesengrund. Dialética do esclarecimento: fragmentos filosóficos. Theodor Adorno, Max Horkheimer. Rio de Janeiro: Zahar, 1985. Tradução de: Guido Antônio de Almeida

ADORNO, Theodor Ludwig Wiesengrund. Educação e emancipação. Rio de Janeiro, $3^{\mathrm{a}}$ edição, Editora: Paz e Terra, 1995. Tradução de: Wolfgang Leo Maar.

ALTHUSSER, Louis. Aparelhos ideológicos do estado. Biblioteca Ciências Sociais, Rio de Janeiro.1992.

BAUDELOT, Christian; ESTABLET, Roger. La escuela capitalista. 10. ed. México: Siglo XXI, 1987.

BOURDIEU, Pierre.; PASSERON, Jean-Claude. A reprodução: elementos para uma teoria de ensino. 3. ed. Rio de Janeiro: Francisco Alves, 1992 
CHARLOT, Bernard. Da relação com o saber: elementos para uma teoria. Tradução Bruno Magne. Porto Alegre: Artmed, 2000.

CHARLOT, Bernard. A mistificação pedagógica: realidades sociais e processos ideológicos na teoria da educação. São Paulo: Cortez. 2013.

CHARLOT, Bernard. Relação com o saber, formação dos professores e globalização: questões para educação hoje. Porto Alegre, Artmed, 2005.

CHAUÍ, Marilena. Ideologia e Educação. Educ. e Pesquisa, São Paulo, v. 42, n. 1, p. 245 257, jan/mar. 2016.

FRANCO, M.A. ; MOTA G; e SILVA, L. Pedagogia crítica: por uma epistemologia crítica e insurgente. No prelo. 2020

FREIRE, Paulo. Conscientização. São Paulo: Cortez, 1984.

FREIRE, Paulo. Pedagogia da autonomia: saberes necessários à prática educativa. São Paulo: Paz e Terra, 1999.

FREIRE, Paulo. Pedagogia da indignação: cartas pedagógicas e outros escritos. São Paulo: UNESP, 2000.

FREIRE, Paulo. Pedagogia do Oprimido. 54ª ed. Rio de Janeiro. Paz e Terra. 1997.

FREIRE, Paulo. Política e educação. São Paulo: Cortez.1993.

GIROUX, Henry. Pedagogia Radical. Subsídios. São Paulo, Cortez. 1983.

GIROUX, Henry. Teoria crítica e resistência em educação: para além das teorias de reprodução. Petrópolis: Vozes, 1986.

GIROUX, Henry. Theory \& resistance in education: a pedagogy for the opposition. GIROUX. Henry. Entrevista. Maio 2019. Disponível em

<https://brasil.elpais.com/brasil/2019/05/09/internacional/1557407024_184967>. Acesso em 23/08 de 2019.

GIROUX, Henry. Theory and Resistance in Education: A Pedagogy for the Opposition. Amherst: Begin \&Garvey.London. 1983.

HABERMAS, Jürgen. Connaissance et intérêt. Paris: Gallimard, 1987.

HABERMAS, Jürgen. Técnica e ciência como ideologia. São Paulo. UNESP, 2014.

Tradução de: Felipe Gonçalves da Silva.

HABERMAS, Jürgen.Teoría de la acción comunicativa: complementos y estudios previos. Madrid: Catedra, 2001. Tradução de. Manuel Jiménez Redondo

LAVAL/DADOT. A nova razão do mundo: ensaio sobre a sociedade neoliberal. Boitempo. 2016. 
MARX, K.: IN: SCHIMIED- KOWARZIK. Práxis e responsabilidade. EDUPUCRS. 2002. P.49

MELO, Rurion. Teoria Crítica e os sentidos da emancipação. Cad. CRH, Salvador, v.24, n.62 Salvador, maio-agosto 2011, p.249-262.

MORROW, Raymond. e TORRES, Carlos .Alberto. Jurgen Habermas, Paulo Freire e pedagogia Crítica: novas orientações para a educação comparada. Educação, Sociedade e Culturas. n. 10. 1998, p. 123-155. Centro de Investigação e Intervenção Educativas (CIIE) da Universidade do Porto. Portugal.

SAVIANI, Dermeval. História das ideias pedagógicas no Brasil. Campinas: Editores associados, 2013.

SILVA, Antonio. J. Pedagogia Crítica e contra Educação. Coimbra: Quarteto editora, 2002.

\section{SOBRE A AUTORA:}

\section{Maria Amélia do Rosário Santoro Franco}

Doutora em Educação pela Universidade de São Paulo (USP), Pós-doutora em Pedagogia, na UFS. Professora/pesquisadora Universidade Católica de Santos. PPGE/UNISANTOS. Líder do Grupo de Pesquisa: Práticas Pedagógicas Pesquisa e Formação. Pesquisador 2 CNPq. E-mail: ameliasantoro@uol.com.br

iD http://orcid.org/0000-0003-3867-5452 